\title{
NOVAS ESTRATÉGIAS DA BIOMIMÉTICA: AS ANALOGIAS NO BIODESIGN E NA BIOARQUITETURA
}

\section{NEW BIOMEDICAL STRATEGIES: ANALYSIS IN BIODESIGN AND BIO-ARCHITECTURE}

\section{Amilton Arruda, Ph.D (UFPE) \\ Theska Laila de Freitas, M.Sc. (UFPE)}

\author{
Palavras Chave \\ Biomimética; Analogia; Biodesign; Bioarquitetura; Ecologia
}

\section{Key Words}

Biomimetics; Analogy; Biodesign; Bioarchitecture; Ecology

\section{RESUMO}

Ao longo da história é possível constatar artefatos de inspiração biológica em diferentes períodos, e em diversas áreas, como a ciência, tecnologia, arquitetura, arte, design, engenharia, dentre outras. Isto tem gerado uma série de pesquisas e projetos que utilizam analogias biológicas com uma abordagem de caráter sustentável e ecológica, condizentes com as necessidades do contexto vigente. Desta forma, o presente estudo refere-se a uma breve revisão bibliográfica para apresentar as origens, definições e princípios da Biomimética, assim como os tipos de Analogias utilizadas no contexto das referências naturais, e ainda, exemplificar algumas de suas aplicações no Biodesign e na Bioarquitetura.

\section{ABSTRACT}

Throughout history, artifacts of biological inspiration can be observed in different periods, and in several areas, such as science, technology, architecture, art, design, engineering, among others. This has generated many researches and projects that use biological analogies with a sustainable and ecological approach, in keeping with the needs of the current context. In this way, the present study refers to a short bibliographical review to present the origins, definitions and principles of Biomimetics, as well as the types of Analogies used in the context of natural references, and to exemplify some of their applications in Biodesign and Bioarchitecture. 


\section{INTRODUÇÃO}

Até poucos anos atrás, para solucionar certos problemas do cotidiano, projetistas de várias áreas buscavam nas disciplinas da Biônica e no Biodesign (...) "ciência dos sistemas em que o funcionamento copiado dos sistemas naturais ou que apresentem características específicas a estes sistemas, ou ainda que sejam análogos" (Arruda, 2002), um apoio e dados no sentido de solucionar tais problemas, aplicando os conhecimentos adquiridos pela observação e estudos das várias formas e sistemas biológicos encontrados na natureza. Esta relação, em alguns casos, tinha um caráter principalmente morfológico e classificável de acordo com sistemas taxonômicos das ciências naturais, que proporcionava um resultado puramente formal e bastante fértil em criatividade dentro do ambiente do design.

Dessa forma, tais ciências foram precursoras e se relacionam com a Biomimética, termo melhor definido e difundido pela pesquisadora americana Janine Benyus em 1997 como: "Uma nova ciência que estuda os modelos da natureza e depois imita-os, inspira-se neles ou em seus processos para resolver problemas humanos". É importante acrescentar que para ela, tais soluções devem ser embasadas na tríade: a natureza como modelo, medida e mentora, buscando solucionar problemáticas do cotidiano do ser humano de forma sustentável e respeitosa, representando uma convivência harmoniosa com o meio ambiente. Portanto, apresenta um caráter fundamentalmente ecológico, prezando valores éticos imprescindíveis ao ser humano, em detrimento ao comportamento autodestrutivo e insustentável da sociedade moderna, pós-revolução industrial. Portanto, procura trazer novos paradigmas e um novo olhar sobre o ambiente natural, focando no todo, no ecossistema, visando estabelecer uma relação mais harmônica e sustentável com o meio ambiente.

A etimologia da palavra Biomimética é oriunda do grego "Bios" (vida) e "Mimesis" (imitação), mas não se limita apenas a uma simples cópia de elementos da natureza. Trata-se da aplicabilidade desses elementos e conceitos em diversos campos através de uma análise complexa e pormenorizada dos atributos desenvolvidos pelos seres vivos que, ao longo do processo evolutivo, demonstraram maior desempenho em relação à seleção natural, corroborando, assim, sua superioridade através da composição física e estrutural.

A natureza construiu um conjunto de estratégias e princípios que culminaram na sua sobrevivência e evolução ao longo de seus 3,8 bilhões de anos de existência. Por isto, olhar para suas soluções e observar como ela funciona, aprendendo suas formas de sobrevivência e meios de evolução durante sua longa jornada é, definitivamente, uma excelente estratégia para se encontrar soluções para vários problemas que a sociedade atual se depara. O objetivo é de transferir o modelo de construção da natureza em áreas de criações humanas, difundindo este método como pesquisa projetual para áreas como a engenharia, a arquitetura e o design, buscando ainda influenciar uma filosofia de autossuficiência.

Dentro de um contexto acadêmico, Arruda (2002) comenta que desde a Bauhaus e a escola de Ulm em seu curso fundamental, já se ofereciam disciplinas em que as análises dos fenômenos naturais, das estruturas, do funcionamento dos organismos vivos eram frequentemente objeto de estudo. Em Ulm, Gui Bonsiepe, professor da escola na época, costumava usar as análises morfológicas de organismos biológicos como escopo didático para melhorar a visão estrutural e a interpretação criativa. Vitor Papanek também foi um dos professores pioneiros a propor o estudo da biônica (elementos naturais) como instrumento de projeto (na época, no California Institute of Arts). Também Bruno Munari, Attilio Marcolli e Aldo Montù na Itália, contribuíram em suas publicações com diversos estudos das estruturas naturais.

Com o passar do tempo, muitos nomes utilizaram a natureza para investigação e criação de artefatos, o que resultou em acúmulo de conhecimento e aprimoramento de técnicas e métodos, sendo a Analogia o método mais comum a ser utilizado para encontrar soluções de concepção com referência no mundo natural, seja através da Biônica, Biomimética ou qualquer biotécnica, e se revela muito útil em contribuir para o processo de interpretação de estruturas naturais para descobrir novos princípios, formas, processos, estruturas.

\section{BIOMIMÉTICA: ORIGENS E DEFINIÇÕES}

Biônica, Biodesign e Biomimética são termos facilmente confundíveis pois suas origens, conceitos, métodos e bases de investigação são realmente muito semelhantes. Fernandes (2012) comenta que ambas as terminologias derivaram da palavra europeia Biotécnica que apareceu como referência no livro datado de 1877 da autoria do Reverendo John George Wood, "Nature's teaching's: Human Invention Articipated by Nature" e posteriormente em 1920 no livro de Raul Francé, "Die Planze als Erfinder" (As Plantas como Inventoras). Mais tarde a palavra sofreu uma derivação, surgindo o termo "Bionics" (Biônica) que se relaciona com a palavra "Bio" (vida) e "onics" de "tecnologics" (tecnologia).

Segundo Arruda (1993), esse termo foi oficialmente apresentado em 1960 num Simpósio nos E.U.A, promovido 
pelas forças aéreas, onde foi utilizado pelo engenheiro e major Jack. E. Stelle que o definiu como: "Ciência dos sistemas cujo funcionamento se baseia em sistemas naturais, ou que apresentam analogias com estes".

Tempos depois em 1969, a palavra Biomimética dá origem ao título de um artigo de Otto Schmitt sendo oficialmente publicada sua definição no dicionário de Webster em 1974:

\footnotetext{
"Trata do estudo da formação, estrutura ou função de substâncias e materiais biologicamente produzidos (como as enzimas ou a seda), e mecanismos e processos biológicos (como a sintetização de proteínas ou de fotossíntese) especialmente para os propósitos de sintetização de produtos similares por mecanismos artificiais que mimetizam os naturais".
}

Depois é a vez de Broeck (1989), outro estudioso do assunto que traz à tona um novo termo, o Biodesign, cuja utilização é dita adequada quando a Biônica é aplicada ao desenho industrial, sendo mais coerente com à atividade de projetos. Neste sentido definiu o Biodesign como o estudo de sistemas e organismos naturais com o propósito de analisar e perceber soluções do tipo funcional, estrutural e formal, para aplicação em resolução de problemas humanos, através de criações tecnológicas, objetos ou sistemas de objetos.

Tanto a Biônica, quanto o Biodesign estudam os princípios básicos da natureza (construtivos, tecnológicos, formais, etc.) para aplicação em soluções tecnológicas, e por isto se tornaram um campo interdisciplinar que combina a biologia com outras áreas, dando origem a diversas outras terminologias correlatas que também são utilizadas com referência nas Bioinspirações ou Biotécnicas, tais como a Bioengenharia, Biomecânica, Bioelectrônica, Bioarquitetura, Bioenergética, Biomaterial, etc.

Apesar de ambas, Biomimética e Biônica, apresentarem fundamentos que remetem a uma mesma base naturalista, recentemente o termo Biônica tem sido mais empregado no sentido da junção da palavra Bios com a eletrônica relacionado com a área da cibernética, na designação da tecnologia à serviço da recriação da natureza, como por exemplo, na criação de próteses artificiais para seres vivos, tais como: orelhas, olhos, mãos, pernas, órgãos, dentre outros.

Já a Biomimética, de acordo com Benyus (1997), traz 3 princípios em seu livro Biomimicry: Innovation Inspired by Nature:
- A natureza como modelo: inspiração e mimese nas soluções da natureza para aplicações práticas;

- A natureza como medida: usa o padrão ecológico como parâmetro para as inovações, pois após 3,8 bilhões de anos de evolução, a natureza aprendeu aquilo que funciona, é mais apropriado, econômico e durável;

- A natureza como mentora: representa uma nova forma de ver e valorizar a natureza, inaugura uma era cujas bases se sustentam não naquilo que se pode extrair da natureza, mas no que se pode aprender com ela.

Essa respeitosa imitação é uma abordagem totalmente nova. Diferentemente da Revolução Industrial, a Revolução Biomimética inaugura uma era cujas bases assentam não naquilo que podemos extrair da natureza, mas no que podemos aprender com ela, tomar emprestado uma ideia para inspirar outras. (Benyus, 1997, p.34.)

Estas últimas abordagens da natureza como medida e mentora apresentam novos valores, que incluem aspectos de sustentabilidade e de respeito à natureza, o que para Janine significa a verdadeira revolução desse campo, pois inspira o sentimento de pertencimento e participação humana, o que constitui uma maior contribuição e abrangência para o termo.

De acordo com Santos (2010), ela colabora com a filosofia do design ambiental, que também tem a visão multidisciplinar onde muitos setores industriais podem substituir o método tradicional de projeto e produção dos bens de consumo pelo "método" da natureza que é bem mais equilibrado e menos oneroso para o ambiente, por isso é um assunto muito pesquisado, de fundamental importância e utilidade para muitas áreas de projetos acadêmicos, centros de pesquisas em universidades e também nos grandes setores econômicos.

Estes princípios atribuíram ao Design uma visão global para a integração da responsabilidade ecológica e sustentável. Este movimento que cresceu sob a fundamentação de "Abordagem responsável ética de design ecológico tem sido descrito como "Bioneers", como design natural, ou o movimento do design natural" (WAHL, 2006, p. 293).

Como nenhuma espécie que destrói o seu habitat natural consegue sobreviver durante um longo período de tempo, a humanidade precisa urgentemente de uma mudança de paradigmas, e um bom caminho para isto está em observar como a natureza opera na criação das suas espécies, sejam vegetais, animais ou minerais, e transpor este mesmo método no desenvolvimento de produtos, sistemas, 
construções e até mesmo serviços, pois os "critérios" observados nos seres vivos mais adaptados, podem servir de base para o desenvolvimento de soluções mais eficientes.

\section{BIOMIMÉTICA E SUAS ANALOGIAS}

$\mathrm{Na}$ antiguidade clássica, a Analogia era abordada pelos filósofos Aristóteles e Platão como uma abstração compartilhada, em que os objetos análogos tinham algo em comum, seja uma ideia, um padrão, uma regularidade, um atributo ou uma função. Como método, ganha um carácter capaz de vencer problemas através de um raciocínio lógico, assim como ajuda na tomada de decisões, nos diferentes campos da criação, percepção e criatividade. Da sua aplicação resulta um amplo conjunto de soluções para diferentes áreas em conformidade com o interesse e conteúdo de cada ciência.

Enquanto método a Analogia tem suas origens no termo Synectics (Sinergia), que corresponde a uma das técnicas mais promissoras para fomentar a criatividade, sua característica mais importante está no uso repetido de associações que levem a abordagem do problema, sob novos pontos de vista. Tornou-se parte do vocabulário dos especialistas, quando William Gordon, em 1963, publicou o livro Synectics, que do grego significa a união de elementos diferentes e aparentemente irrelevantes.

Segundo Gordon (1963), a Synetics funciona num misto de teoria e técnica. Como teoria, estuda o processo criativo e os mecanismos psicológicos da atividade criativa, com o objetivo de aumentar as chances de pessoas obterem sucesso na resolução de problemas. Como técnica, fornece uma repetição capaz de aumentar as chances de chegar a soluções criativas pelo procedimento de aproximação. Ele também define os 4 tipos de Analogias:

- Analogia Direta: Descreve a verdadeira comparação de fatos, conhecimentos, objetos, organismos, que possuam algum grau de semelhança;

- Analogia Pessoal: Descreve uma personificação imersiva no problema. Começando com a pergunta: Se eu fosse...? Assim ocorre uma fusão imaginária entre a pessoa e o objeto ou situação, permitindo uma visão interna sobre os sentimentos, pensamentos e formas de atuação específicas para cada caso. (Se eu fosse um...me sentiria como?);

- Analogia Simbólica: Seleciona uma palavra-chave e pergunta-se qual a sua essência, para então experimentar ou sentir os significados descobertos; usa imagens objetivas e impessoais para descrever o problema por uma resposta poética; Uma vez criada é uma torrente de associações;
- Analogia Fantástica: Deixa de lado o pensamento lógico e racional. Partindo de um problema específico se deixa a porta aberta à fantasia, conduzindo a soluções imaginárias que estão fora do universo possível.

A técnica fornece grande atenção aos elementos emocionais, irracionais e inconscientes na busca criativa; no entanto, é essencial não perder de vista também a reflexão racional. Consiste em afastamento do problema, o relacionando com conceitos, ideias e imagens que ele inspira num processo chamado de cruzamento, para daí se extrair soluções.

A Biomimética e demais Biotécnicas a utilizam para buscar soluções exclusivamente com referência na Natureza. Para Steadman (1988) existem alguns tipos específicos de Analogias relacionadas ao mundo natural, são elas:

- Analogia Orgânica: Busca encontrar o equilíbrio entre os organismos humanos, as obras de arte e os sistemas mecânicos.

- Analogia Classificatória: Observa os métodos estabelecidos da botânica e zoologia para aplicação na Arquitetura e no Design.

- Analogia Anatômica: Traz uma sistemática de trabaIho que estuda a estrutura do esqueleto animal comparando-os com as construções da engenharia.

- Analogia Darwiniana: Busca explicar que os objetos e as construções são feitos através de cópias repetidas através dos tempos, como acontece com a evolução natural.

Arruda (2002) descreve a Analogia Sensorial como o estudo dos sistemas de controle e transmissão de informação de organismos vivos para transpor em modelos eletrônicos e mecânicos, com objetivo de reduzir e otimizar ao máximo seus resultados. Além destas, Soares (2016) discorre também sobre os 3 tipos de Analogias que para ela resumem de maneira eficaz o método de Analogia relacionado com a Biomimética, a Morfológica, a Funcional e a Simbólica.

Bonsiepe (1978) define a Analogia Morfológica como a busca experimental de modelos elaborados da tradução das características estruturais e formais para transpor em projetos. Sendo assim, procura estudar e analisar o porquê da forma natural, as inter-relações da sua geometria, observando e compreendendo suas texturas, atentando para as características do shape (forma externa), das partes e componentes, dos detalhes de alguma parte a nível macro ou microscópico, assim como, para as suas formas estruturais.

A análise de fenômenos morfológicos da natureza facilita e estimula a capacidade de percepção de detalhes e princípios presentes em sua estrutura. Ideias inovadoras 
vêm surgindo de pesquisas sobre sistemas e propriedades naturais que nem sempre se traduzem apenas na estética, mas que a forma natural favorece também o ganho em eficiência. Neste sentido Versos (2010) traz um bom exemplo através do Trem-bala Shinkansen desenvolvido pelo engenheiro Eiji Nakatsu que teve como referência, a forma do bico alongado do pássaro Martim-Pescador, que facilita o mergulho sem espirrar água em busca de sua refeição. Visando solucionar um dos grandes problemas do trem bala que é a vibração e o barulho, o engenheiro buscou inspiração no formato do bico deste pássaro, o que resultou numa melhora significativa com um trem-bala $10 \%$ mais rápido, consumindo $15 \%$ menos energia, e ainda, reduzindo a pressão do ar em 30\% em relação ao modelo anterior.

Figura 1: SHINKANSEN (Japão), trem bala de alta velocidade mais rápido do mundo, redesenhado tendo como base o bico de um Martin-pescador.

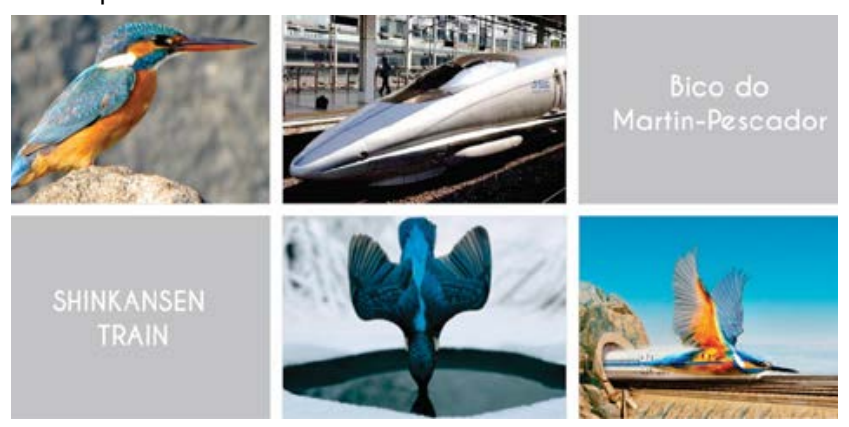

Fonte: VERSOS, 2010

Já a Analogia Funcional procura estudar o funcionamento do sistema físico e mecânico natural; tenta compreender quais funções desempenham tanto no todo, quanto em suas partes e componentes. Em outras palavras são evidenciados os atributos funcionais, qualidades específicas que se pode mimetizar da estrutura natural analisada, uma vez que os organismos naturais desenvolveram habilidades complexas e altamente adaptáveis, a ideia é mimetizar essas aptidões funcionais e aplicá-las em artefatos artificiais.

Através de parcerias entre pesquisadores de áreas de projetos com departamentos de biologia que se utilizam de informações específicas de características do mundo natural, conseguem acesso a descrição das funções encontradas em alguns organismos vivos que podem orientar a geração de ideias para solução de problemas projetuais.

A vantagem desta Analogia é que se identificando estas estratégias e funções se pode aplicar em mais de um tipo de artefato, servindo para uma ou mais soluções como o caso do estudo das folhas de lótus, na qual o pesquisador Barthlott, identificou as funções de repelir a água e de autolimpeza das suas superfícies. Isto acontece devido ao ângulo formado pelas suas micro e nanoestruturas cerosas, que impedem o contato com a água, fazendo-a rolar e formar gotas que vão recolhendo a sujeira pelo caminho. Com isto, se identificou que superfícies ásperas em nano escala são mais hidrofóbicas que superfícies mais lisas. Na folha de lótus, a área de contato real é de apenas 2-3\% da superfície das gotas. (VERSOS, 2010)

Tal analogia funcional foi aplicada comercialmente em produtos como a tinta Lotusan e também em outros materiais e produtos, tais como os têxteis, a madeira ou o vidro, através de sprays (BASF Lotus Spray) que simulam o mesmo efeito da planta. Na tinta, ao criar micro saliências, ela repele a água, se auto limpando e resistindo a manchas durante décadas. Apesar de se replicar estas microestruturas, os artefatos gerados não se referem a forma das folhas em si e sim a função identificada de hidrofobia e autolimpeza. Como pensa Soares (2016), enquanto morfologicamente a Analogia gera soluções limitadas a uma forma, funcionalmente elas podem gerar múltiplas aplicações.

Figura 2: LOTUSAN (Alemanha), tinta que repele a água e resiste a manchas durante décadas, inspirada nas microestruturas das folhas de lótus.
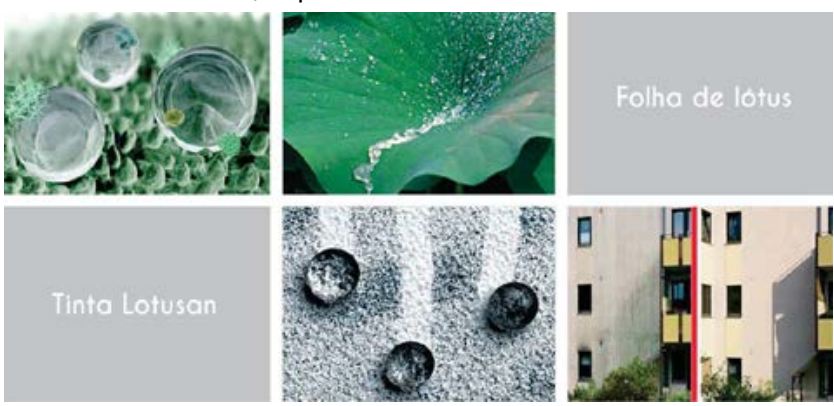

Fonte: VERSOS, 2010

Por fim, na Analogia Simbólica estão os casos de imitação mais abstratos que não correspondem a fidelidade das formas nem necessariamente das funções, em que os artefatos produzidos possuem correspondência com aspectos da estrutura natural analisada com certo grau de abstração inerente das interpretações autorais. Um exemplo expressivo deste tipo de Analogia são as excêntricas e orgânicas construções do arquiteto espanhol Antoni Gaudí, com predominância por uma arquitetura biomórfica, cheia de curvas e contracurvas, onde elementos da natureza são desenhados em vários detalhes. Experimentando formas e materiais novos, se dedicou à cada esquina e a cada pormenor numa organicidade que acabou por caracterizá-lo. (SOARES, 2016) 
Figura 3: Exemplo de analogia simbólica nas obras de Antoni Gaudì.

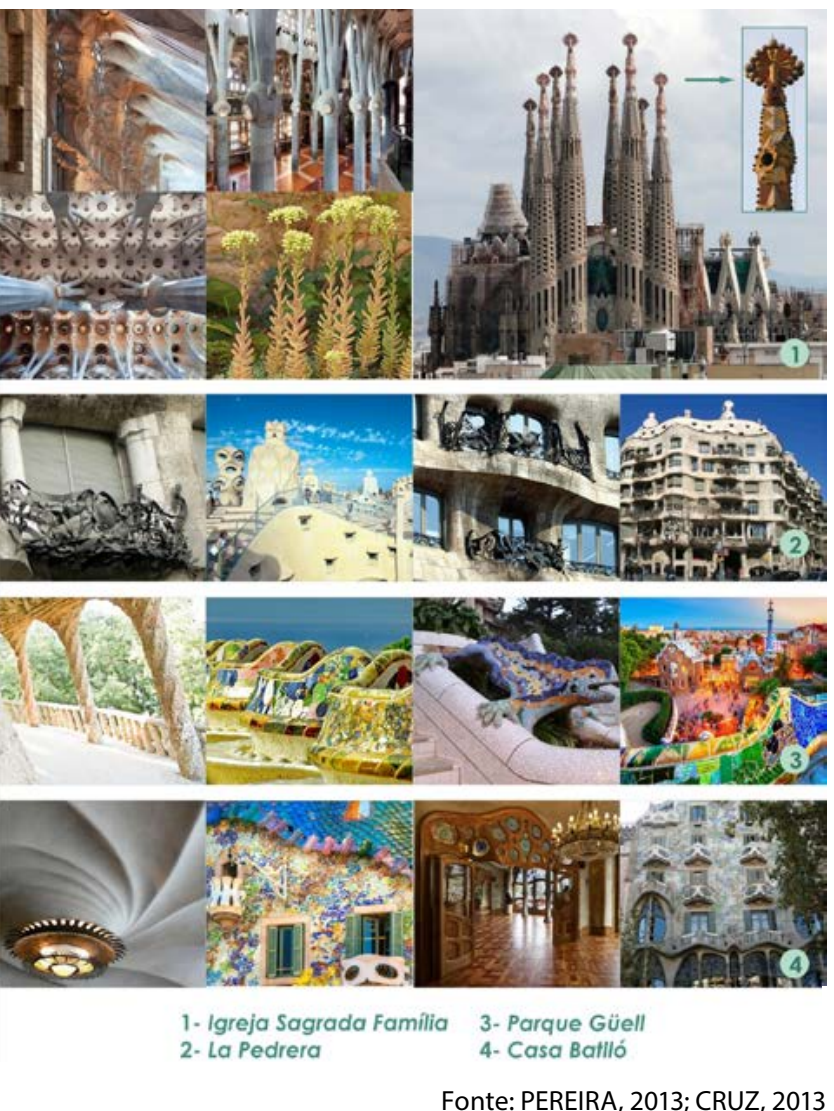

etc. Todas estas, obras artísticas com espaços cavernosos, cores, texturas e uma luminosidade tão peculiar, cuja forma resultante refletem a tradução pura da interpretação pessoal de Gaudí da sua visão de natureza.

\section{EXEMPLOS DE ANALOGIA NO BIODESIGN E NA BIOARQUITETURA}

Leonardo Da Vinci, considerado por muitos o maior gênio da história devido a sua multiplicidade de talentos (matemático, engenheiro, arquiteto, botânico, inventor, anatomista, pintor, etc.), também foi pioneiro no uso da Analogia de estruturas naturais, como pode ser observado em vários dos seus estudos de projetos. Devido à cultura material e aos paradigmas da época, completamente diferentes dos de hoje, observar e obter inspiração da natureza era uma tarefa considerada privilegiada e para poucos indivíduos. Apesar dos muitos inventos e projetos de Leonardo não terem sido construídos na época, contudo tratavam-se claramente de investigações de estruturas naturais através de técnicas analógicas, como o famoso exemplo da Máquina Voadora, inspirada nos estudos de voo dos pássaros, que serviram para formular alguns dos princípios utilizados atualmente na engenharia aeronáutica e engenharia mecânica. (Arruda, 2002)

Figura 4: Estudos do voo de pássaros e Máquina para bater asas "Ornitóptero" de Leonardo da Vinci.

D'Arcy Thompson (1961) relembrando sobre a emblemática obra da igreja Sagrada Família em Barcelona. Segundo Pereira (2013), Gaudí confere torsões parabólicas à fachada, fazendo uso de hipérboles e espirais em várias partes da construção, preenchendo a obra de motivos vegetais destacando a sua atitude naturalista e orgânica, num contrassenso da arquitetura gótica da época, em que para ele, as linhas retas não refletiam as leis da natureza com suas formas curvas. Cruz (2012) também reforça o "espírito natural" de Gaudí através da disposição das folhas, caules, raízes das plantas, e também nas pétalas das flores desta igreja, onde as particularidades remetem para uma floresta ou mundo subaquático, apresentando no interior, um aspecto panorâmico de bosque encantado, onde os jogos de luzes e os estreitos pilares densificam essa atmosfera, tendo as torres principais visíveis na fachada inspiradas pela planta Sedum Sediforme, pontuadas por pináculos ou flores. Além da Sagrada Família, Cruz (2012) também cita outros exemplos desse tipo de Analogia, reflexos do olhar cheio de simbolismo de Gaudí, nas varandas do La Pedrera Casa Milá, com delicadas folhas ornamentadas; no Parque Güell, com elementos biomorfos, tais como os répteis e/ou dragões; na Casa Batlló, coberta de "escamas",
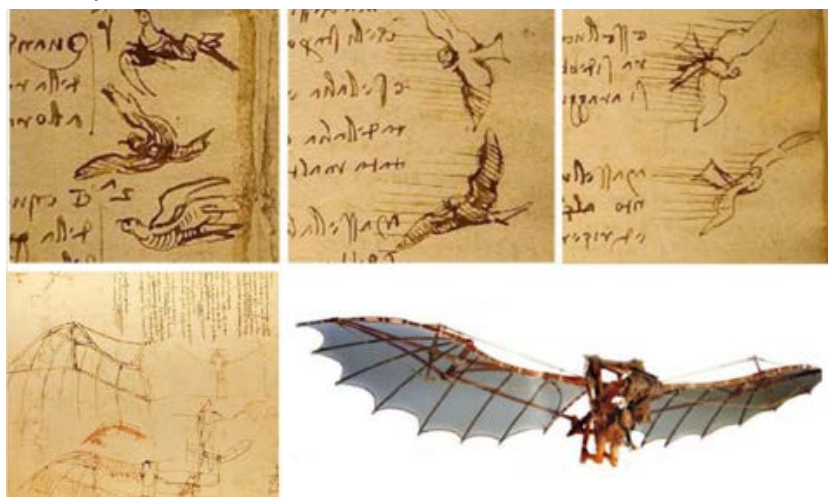

Fonte: CRUZ, 2012, p.19

No contexto atual são vários os exemplos de Biodesign que utilizam analogias da Natureza, alguns casos curiosos como o exemplo do Velcro, criado em 1948, pelo engenheiro suíço Georges de Mestral, marca registrada da Dulpont $^{\circledR}$. Trata-se de um conector formado por duas faces opostas: uma é revestida por pequenos ganchos de plástico e a outra por pedaços de voltas plásticas. Seu inventor obteve esta ideia a partir de uma semente de Arctium (planta da família das Asteraceae) que aderia firmemente em suas roupas e no pelo do seu cachorro em 
que intuiu que o motivo seria devido a sua forma estrutural. Desta simples curiosidade e observação resultou um produto que é utilizado em larga escala nas mais variadas peças de vestuário e outras áreas da indústria.

Versos (2010) também cita um exemplo aplicado de Analogia Funcional com a pesquisa das escamas da pele do tubarão, responsáveis pelo desempenho hidrodinâmico do animal. Segundo especialistas, a água desliza através das micro ranhuras da pele do animal reduzindo a fricção. A aplicação desta pesquisa em roupas de natação da marca Speedo Fastskin é utilizada hoje por campeões olímpicos. A textura destas vestimentas baseada nos "dentículos" da pele de tubarão em formato de $\mathrm{V}$, tem como vantagens, a redução da resistência passiva de cerca de $4 \%$ e também da vibração muscular, aumentando a velocidade e o desempenho dos atletas. Em 2008, o nadador Michael Phelps, maior medalhista olímpico, conseguiu atingir um novo recorde mundial utilizando o novo tecido que incrementou significantemente a performance do atleta.

Figura 5: FASTSKIN da marca Speedo (Austrália), roupa de banho para competição de natação que imita a função de eficiência hidrodinâmica da pele de tubarão, resultando na redução do atrito e consequente aumento de velocidade.
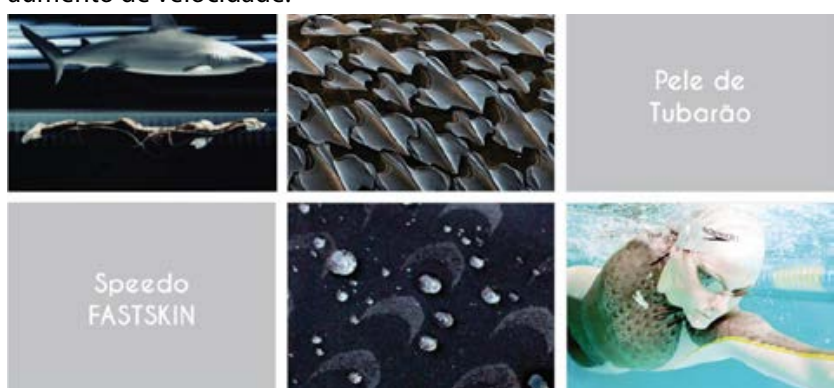

Fonte: VERSOS, 2010

Nos tubarões estas micro escamas também impedem a fixação de pequenos crustáceos e de algas, uma oportunidade de aplicação em novos projetos, como por exemplo, revestimentos sintéticos que podem revestir cascos de navios a fim de reduzir o atrito, poupando energia e também esse inconveniente biológico que causa regulares manutenções. Mais um caso em que a Analogia Funcional pode gerar soluções para aplicação em diversos artefatos, pois não se limitando apenas a forma do animal investigado, e focando na função que se identifica a partir dele, pode-se prever novas aplicações para o Biodesign.

Um outro exemplo igualmente interessante de Analogia, neste caso, morfológica, é o Bionic car da marca Mercedes-Benz, a referência natural desta vez é a forma e estrutura óssea hidrodinâmica do peixe-cofre, que proporciona alta resistência à estrutura do carro através do uso mínimo de material. Portanto, embora tenha sido usado o nome "Bionic", provavelmente por acreditarem que o significado seja a aliança entre a biologia e a tecnologia, é clara a participação de conceitos da Biomimética no automóvel, por se ter relevância nos aspectos de sustentabilidade, apresentando excelente aerodinâmica e peso reduzido com um consumo de 4,3 litros por $100 \mathrm{~km}$, significando $20 \%$ mais economia em comparação aos veículos da mesma classe, e ainda, redução das emissões de óxido de nitrogénio em cerca de $80 \%$. (VERSOS, 2010)

Figura 6: BIONIC CAR da marca Mercedes-Benz (Alemanha), automóvel desenvolvido com base na forma e estrutura hidrodinâmica do peixe-cofre.
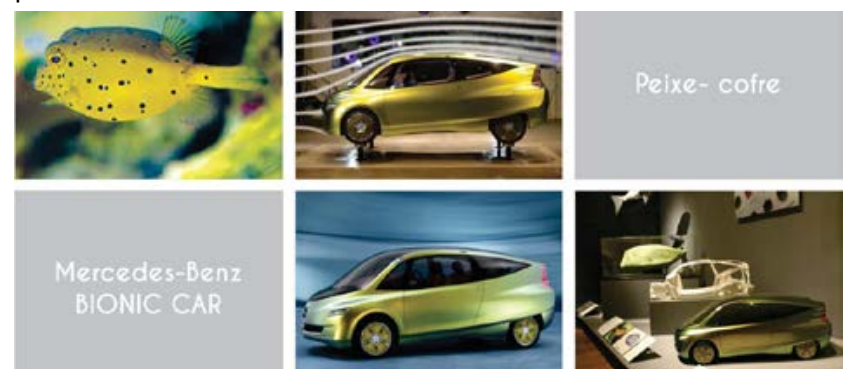

Fonte: VERSOS, 2010

Outros exemplos mais perceptíveis de Biodesign, também devem ser lembrados, como as barbatanas utilizadas pelos mergulhadores, inspiradas nas patas dos cisnes e na forma como estas interagiam com a água; as ventosas criadas a partir da analogia morfológica e funcional das ventosas dos polvos, compreendendo a mesma função de aderência; os alicates baseados na forma da pinça do caranguejo; e até mesmo a camuflagem militar inspirada na camuflagem animal.

Figura 7. Exemplos de Analogia Morfológica - Coluna estrutural/Folha da palmeira leque; Cadeira/Forma estrutural da borboleta; Arame farpado/Espinhos e Alicate/Pinça do caranguejo.

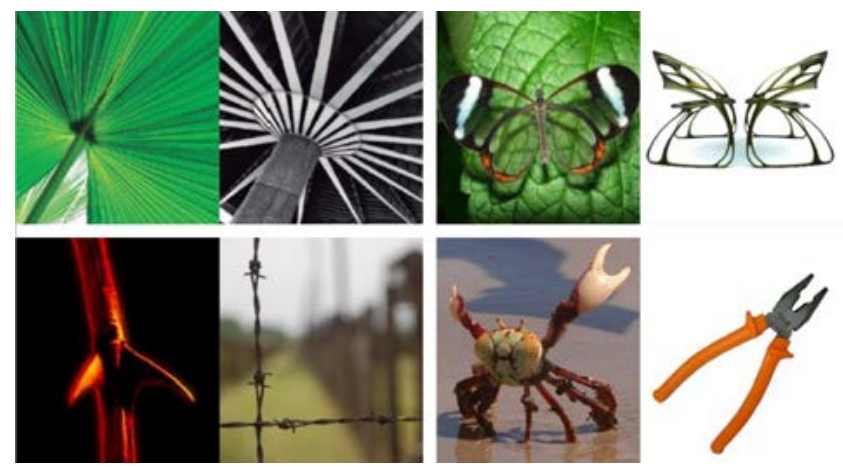

Fonte: Elaborada pela autora, do banco de imagens do laboratório do BIODESIGN 
Já na Arquitetura, um nome bem expressivo na atualidade para a Bioarquitetura, é Santiago Calatrava, artista, arquiteto e engenheiro espanhol que tem como característica marcante em sua obra a referência à dinâmica dos organismos vivos, principalmente nos esqueletos e na impressão de movimento que estes conferem às suas edificações, inclusive em suas obras estruturais é possível perceber essa rica imaginação da natureza, em particular de esqueletos animais através do uso de elementos metálicos e do cimento armado, intensificando o porte das suas construções.

Talvez justamente por ter tido uma formação também artística, essas analogias tenham um caráter simbólico tão característico que se traduzem numa identidade em sua Arquitetura. Segundo Dias (2014), por ter cursado a Academia de Arte de Valência (ES), antes de se formar em Arquitetura e posteriormente em Engenharia, Calatrava, certamente incorporou ao seu estilo um viés muito mais artístico e notadamente calcado na poética. Declaradamente ele afirmava ser adepto do estudo natural: "Em determinado período dediquei-me ao estudo das formas orgânicas com as quais o meu trabalho tem algumas analogias. É o resultado de uma escolha clara e não tanto do processo de solução de certo problema estrutural." (LEFAIVRE \& TZONIS, 2011, p.78)

Característica recorrente, e por muitos considerada sua marca registrada, é esse desejo de buscar sempre unir estrutura e movimento. Elementos articulados que, apesar da aparência sólida, são ao mesmo tempo leves e dinâmicos podem ser encontradas diversas vezes em suas coberturas e pontes. Para tal, sempre procura referenciar estruturas naturais que possuem em sua constituição esqueletos e situações de articulações. Pereira (2013) sugere que o pássaro é uma referência clássica do elemento ar, tornando coerente o uso deste animal como inspiração na construção, por exemplo, de aeroportos. $O$ pavilhão de Calatrava em Milwaukee (USA) oferece um cenário simbólico tão expressivo que chega a ser dramático visto de qualquer ponto da cidade. Simetricamente balançado com duas asas modeladas por setenta e duas cordas metálicas finas, presas a uma espécie de espinha dorsal; o edifício forma o que parece ser uma gigante estrutura cinética.

O Lyon-Saint Exupéry Airport Railway (1994/FRA), também exemplifica uma Bioarquitetura onde as referências formais nesse projeto são ainda mais explícitas que em Milwaukee. A metáfora do voo contida no projeto também é evidente, assim como o seu perfil remete a um porco-espinho ou papa-formigas (até mesmo o olho humano), efeito acentuado pela coloração do edifício. A estrutura é rica em alusões biomórficas, apesar de Calatrava se basear mais na exploração da física e do equilíbrio de massas e forças do que propriamente no shape dos animais. (PEREIRA, 2013)

Mais um exemplo de projeto grandioso dele são os 35 hectares da Ciudad de las artes y las Ciencias em Valência (ESP), dentro deste complexo, o famoso teatro Planetarium/IMAX que referencia o olho humano, onde a "pupila" é uma cúpula hemisférica do teatro IMAX, que se transforma em um globo através do seu reflexo na piscina. A "pálpebra" de tiras verticais articuladas de metal é móvel e pode ser levantada para permitir a visualização da paisagem do entorno e da piscina.

No Brasil em 2015 foi inaugurado o Museu do Amanhã, obra primorosa de Calatrava no Rio de Janeiro. O projeto possui um telhado em alavanca com suas grandes "asas" móveis com uma estrutura da fachada que se expande em quase todo o comprimento do cais, enfatizando a extensão para a Baía de Guanabara e minimizando a largura do edifício. Um espelho d'água rodeia o museu por fora e é usado para filtrar a água que está sendo bombeada da baía e liberada de volta no final do píer, o que dá aos visitantes a impressão de que o museu está flutuando, numa analogia a um animal marinho. Antenado com as abordagens sustentáveis da arquitetura vigente, o edifício funciona fazendo uso dos recursos naturais do entorno, como a água que vem da baía, bem como a energia solar coletada através de painéis fotovoltaicos, integrados às "asas" móveis do telhado, que podem se ajustar dinamicamente para o ângulo ideal do sol, alguns recursos que, segundo Calatrava, fornecem importantes valores educacionais. 
Figura 8: Exemplos biomiméticos das obras de Santiago Calatrava.
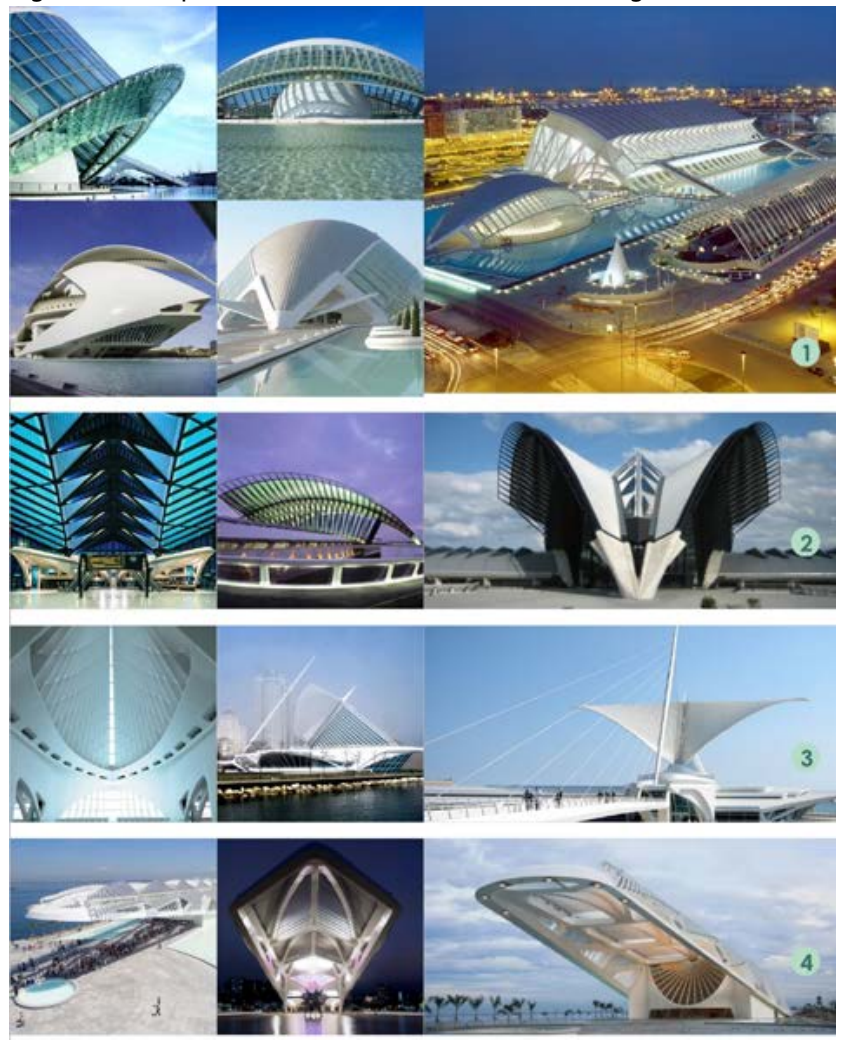

1. Cludad de las Artes y las Ciencias (ESP) 3-Milwaukee Art Museum (USA) 2- Lyon-Saint Exupéry Airport (FRA) 4- Museu do Amanhā (RJ/BRA)

Fonte: Santiago Calatrava

\section{CONCLUSÕES}

Embora utilizar a Natureza como referência para as criações não seja algo propriamente novo, lembrando das invenções de Leonardo da Vinci, das inspirações arquitetônicas de Gaudí e dos muitos casos em que o Homem fez analogias da natureza para suas criações, observando e aprendendo dela, percebe-se que durante esse processo de "evolução" de conhecimento, de desenvolvimento tecnológico e de sistemas financeiros, este aprendizado foi se tornando uma realidade cada vez mais distante que tem desencadeado uma série de outros problemas que interferem não apenas no bem estar do homem, mas no de todo o ecossistema, o qual está incluído e dele é dependente.

Desta forma, diante de uma infinidade de opções e métodos para fazer Design, uma resposta satisfatória está em utilizar a Biomimética em que podem ser utilizados vários tipos de Analogias de estruturas naturais para se projetar de maneira mais eficiente, funcional e durável, visto que, imitar uma natureza que depois de 3,8 bilhões de anos de evolução, os fracassos se tornaram fósseis, e o que permanece é fruto do segredo da sobrevivência, torna coerente a afirmativa de que quanto mais o mundo artificial se parecer com a natureza e funcionar como ela, maior a probabilidade de sucesso adaptativo no planeta.

Foram identificados vários exemplos da aplicação dos princípios biomiméticos no cotidiano, variando de um alicate inspirado nas pinças dos caranguejos a um automóvel aerodinâmico baseado na forma do Peixe-Cofre; ou ainda nos monumentos arquitetônicos exuberantes, apresentados pelo arquiteto espanhol Santiago Calatrava, projetista que sempre atribuiu analogias biológicas ao seu trabalho, como o edifício Planetário, que remete sua forma ao olho humano, e o Museu do Amanhã, com o uso de recursos renováveis no local.

Mas o conhecimento acumulado em todos o processo evolutivo de vida na Terra, representa ainda potencial a ser pesquisado e utilizado, em que todos os exemplos de Biodesign e Bioarquitetura citados significam apenas uma pequena parcela do que se tem aproveitado, existindo uma grande parte ainda desconhecida e negligenciada a ser desbravada, tarefa esta que ainda está longe de ser completamente dominada, necessitando de um grande incentivo e disseminação destes conteúdos, multidisciplinaridade e melhor aperfeiçoamento dos instrumentos utilizados, em prol de uma maior consistência e profundidade dos conhecimentos adquiridos e gerados, com mais foco para resolver os problemas gerais do homem utilizando tais técnicas.

Portanto, observar como a Natureza opera na criação das suas espécies, sejam vegetais, animais ou minerais, pode-se traduzir de maneira análoga no desenvolvimento de produtos, sistemas, construções e até mesmo serviços, pois os "critérios" observados nos seres vivos mais adaptados, podem servir de base para o desenvolvimento de soluções mais eficientes. Através de um olhar atento às suas soluções, existe uma infinidade de bons exemplos de eco eficiência, através de organismos que constroem com o mínimo de desperdício de materiais e energia, e que ainda coexistem em harmonia com a biosfera. Evidenciar esta nova forma de perceber a natureza é bem diferente da ideia de exploração a que geralmente o Homem a tem associado, por isto a Biomimética reflete uma filosofia que promove soluções sustentáveis para problemas reais que afligem o homem moderno, cujos valores éticos envolvendo o meio ambiente foram se desfazendo ao longo do tempo e que hoje devem ser retomados, a fim de preservar o mundo que é a sua morada, mas não exclusivamente sua.

\section{REFERÊNCIAS}

ARRUDA, A. (2002). Bionic Basic: Verso un nuovo modello di ricerca progettuale. 175 p. Tese (doutorado) 
- Univesidade Politécnico de Milão, Dottorato di Ricerca in Disgno Industriale e Comunicazione Multimediale.

(1993) Verso una didattica nel campo biônico: ipotesi per lo sviluppo di una strategia progettuale. 185 p. Tese (mestrado) - Istituto Europeo di Disegn di Milano, Centro Ricerche in Strutture Naturalli.

BENYUS, J. M. (1997). Biomimética: Inovação inspirada pela natureza. $6^{\mathrm{a}} \mathrm{ed}$. São Paulo: Editora Cultrix.

BONSIEPE, G. (1978). Teoria y Práctica del Diseño Industrial. Barcelona, Editorial Gustavo Gilli, p.124-34.

BROECK, F. V. (1989). O uso de analogias biológicas. Revista Design e Interiores. São Paulo: n.15, p.97-100.

CRUZ, A. J. A. B. (2012) Arquitectura [bio]lógica,uma análise da obra de Frei Otto. 229p. Dissertação de Mestrado Integrado em Arquitectura Faculdade de Ciências e Tecnologia da Universidade de Coimbra, Coimbra, Departamento de Arquitectura.

DIAS, E. (2014) A natureza no processo de design e

FERNANDES, M. (2012) Biomimética como conceito para uma embarcação na Ria de Aveiro. Dissertação (Mestrado) - Universidade de Aveiro, Aveiro/Portugal, Departamento de Design.

GORDON, W. J. J. (1963). Sinética: El desarrollo de la capacidad creadora. México: Herreros Hnos. S. A.

LEFAIVRE, L.; TZONIS, A. (2011). Santiago Calatrava. São Paulo: Folha de São Paulo.

PEREIRA, Inês, V. M. (2013). Arquitectura Biônica, narrativas de analogias biológicas na Arquitectura. 171p. Dissertação (Mestrado) - Departamento de Arquitectura, Porto, Faculdade de Arquitectura da Universidade do Porto.

SANTOS, C. (2010). O desenho como processo de aplicação da biomimética na arquitetura e no design. Revista TÓPOS. V. 4, N² 2, p. 144 - 192. Universidade Estadual Paulista, Presidente Prudente.

SOARES, T. (2016) A Biomimética e a Geodésica de Buckminster Fuller: Uma Estratégia de Biodesign. 315

p. Dissertação (mestrado) - Universidade Federal de Pernambuco, Recife, Departamento de Design do Centro de Artes de Comunicação.

STEADMAN, P. (1988). The evolution of designs biological analogy in architeture and applied art, $1^{\text {a }}$ ed., Cambridge, Cambridge University Press.

THOMPSON, D. W. (1961). On growth and form. 1aed., Cambridge, Cambridge University Press.

VERSOS, C. A. M. (2010). Design biônico: A natureza como inspiração criativa. Dissertação (Mestrado). 186p Universidade da Beira Interior, Covilhã, Departamento de engenharia Eletromecânica.

WAHL, D. C. (2006). Bionics vs. Biomimicry: From control of nature to sustainable participation in nature. New Forest, WIT Transactions on Ecology and the Environment. 